\title{
El cíngulo dental
}

\section{Dental cingulum (cingulate)}

\author{
Sandra Moreno, ${ }^{*}$ Freddy Moreno*
}

El cíngulo dental corresponde a una característica morfológica con escasa investigación en el contexto odontológico, pero de amplio estudio en el contexto biológico y antropológico. Esta estructura morfológica desconocida o incomprendida por muchos odontólogos se constituye en el punto de origen de diferentes rasgos morfológicos dentales. Tradicionalmente, el cíngulo dental se ha definido como la porción de esmalte que forma una protuberancia convexa en el tercio cervical de la superficie palatina y lingual de la corona anatómica de los dientes incisivos y caninos superiores e inferiores; de allí que en el contexto odontológico haya sido considerado como una estructura morfológica exclusiva de los dientes incisivos y caninos -como clase- de la dentición humana. ${ }^{1}$

Sin embargo, en el contexto bioantropológico el cíngulo dental fue definido como un puente de esmalte que en el tercio cervical conecta la base de los lóbulos de los dientes anteriores y de las cúspides de los dientes posteriores para proteger los tejidos gingivales de las posibles injurias ocasionadas por fragmentos de alimentos duros durante la masticación de los mamíferos. ${ }^{2}$ Esta función original, relacionada con la protección gingival de los mamíferos primitivos, fue complementada posteriormente con la conformación del molar tribosfénico, la cual explica que el cíngulo dental se constituyó en un refuerzo estructural para disipar las fuerzas generadas desde las cúspides durante la oclusión. ${ }^{3}$ Por tanto, el cíngulo dental configura macro-estructuralmente una protuberancia convexa en la superficie palatina y lingual de incisivos y caninos superiores e inferiores, y una plataforma bien desarrollada que rodea el tercio cervical en los molares superiores e inferiores. ${ }^{1,4}$

De acuerdo con la teoría tritubercular -que explica el desarrollo evolutivo de los dientes mamíferos- los dientes posteriores cuentan con un collar de esmalte denominado cíngulo (molares superiores) o cingúlido (molares inferiores) que circunscribe, a la altura del tercio gingival, la corona de todos los dientes a manera de una saliente estilar-stylar shelf- de la cual emergen durante la odontogénesis diferentes rasgos morfológicos dentales como el talón cuspídeo y los lóbulos que conforman el cíngulo mismo en los dientes anteriores y los denominados tubérculos o cúspides paramolares (paraestilos en molares superiores y paraestílidos en molares inferiores) presentes en las superficies vestibulares, palatinas o linguales de los molares superiores e inferiores respectivamente, como es el caso del protoestilo -cúspide de Carabelli-, el paraestilo y el protostílido. ${ }^{5-8}$

Si bien en el contexto antropológico la observación, registro y análisis de la morfología dental a través de estos rasgos morfológicos dentales se ha constituido en una invaluable fuente de información para estimar las relaciones biológicas entre poblaciones humanas pasadas y presentes, ${ }^{9}$ en el contexto odontológico el cíngulo (el de los dientes anteriores) ha sido relegado a ser descrito como un factor anatómico proclive para la acumulación de placa bacteriana y aumento de la posibilidad de desarrollar caries ${ }^{9-11}$ o a la generación de interferencias oclusales a manera de puntos de contacto prematuros. Ambas situaciones son frecuentemente solucionadas con ameloplastia selectiva y tratamientos restauradores. ${ }^{12,13}$

Por tanto, resulta fundamental contrastar el concepto bioantropológico del cíngulo ante la controversial falta de conocimiento del papel evolutivo de esta estructura morfológica, razón por la cual se debe considerar:

1. El cíngulo dental corresponde a una estructura morfológica que surgió durante la evolución de los pri-

\footnotetext{
* Odontólogo Magíster en Ciencias Biomédicas, Profesor de la Escuela de Odontología de la Universidad del Valle (Cali, Colombia), Profesor de la Pontificia Universidad Javeriana (Cali, Colombia).
}

(C) 2016 Universidad Nacional Autónoma de México, [Facultad de Odontología]. Este es un artículo Open Access bajo la licencia CC BY-NC-ND (http://creativecommons.org/licenses/by-nc-nd/4.0/).

Este artículo puede ser consultado en versión completa en http://www.medigraphic.com/facultadodontologiaunam 
meros mamíferos a manera de un collar que rodea la corona de todos los dientes -anteriores y posteriores- a nivel del tercio cervical, cuyas funciones eran la protección de los tejidos periodontales ante la posible injuria causada por alimentos duros, y el refuerzo del esmalte cervical para absorber las fuerzas provenientes de las cúspides funcionales durante la masticación.

2. En los dientes anteriores el remanente evolutivo del cíngulo se expresa en la superficie palatina y lingual a manera de una prominencia constituida por un sistema de lóbulos y surcos de amplia variabilidad morfológica cuya función ha sido asociada al direccionamiento de los fragmentos de alimentos durante la incisión.

3. El cíngulo en los dientes anteriores se constituye en la plataforma de origen de rasgos morfológicos dentales como lo son el tubérculo dental -el cual puede estar presente tanto en la superficie vestibular como en la palatina y lingual de los incisivos superiores e inferiores respectivamente- y el surco interrumpido.

4. En los dientes posteriores el cíngulo se constituye en la plataforma de origen morfogenético de las denominadas cúspides paramolares -cúspide de Carabelli, paraestilo y protostílido-, siendo la expresión cuspídea de éstas el remanente evolutivo de esta estructura.

5. Al involucionar el cíngulo en los dientes posteriores, el esmalte del tercio cervical coronal próximo a la unión amelocementaria, se torna muy delgado, quedando expuesto a la fractura producto de las fuerzas tensiles provenientes de la función masticatoria, lo cual genera un tipo de lesión asociada reconocida como abfracción.

\section{REFERENCIAS}

1. Berkovitz BKB, Holland GR, Moxham BJ. Oral anatomy, histology and embryology. 2nd edition. London: Mosby International; 2002.

2. Reynolds SH. The vertebrate skeleton. 2 nd edition. Cambridge: Cambridge University Press; 1897.

3. Kermack DM, Kermack KA, Mussett F. The Welsh pantothere Kuehneotherium praecursoris. Zool J Linn Soc. 1968; 47: 407423.

4. Hillson S. Teeth. Manuals in archaeology. 2nd edition. Cambridge: Cambridge University Press; 2005.

5. Osborn HF. The evolution of mammalian molars to and from the tritubercular type. The American Naturalist. 1888; 22 (264): 1067-1079.

6. Kraus BS. Morphologic relationships between enamel and dentine surfaces of lower first molar teeth. J Dent Res. 1952; 31: 248-256.

7. Butler PM. Some functional aspects of molar evolution. Evolution. 1972; 26 (3): 474-483.

8. Duque JF, Ortíz M, Salazar L, Mejía C. Mamíferos: evolución y nomenclatura dental. Rev Estomat. 2009; 17 (2): 30-44.

9. Scott GC, Turner II CG. The anthropology of modern human teeth: dental morphology and its variation in recent human populations. London: Cambridge University Press; 1997.

10. Rodríguez JV. Dientes y diversidad humana: avances de la antropología dental. Bogotá: Universidad Nacional de Colombia; 2003.

11. Hernández J, Villavicencio J, Arce E, Moreno F. Talón cuspídeo: reporte de cinco casos. Rev Fac Odontol Univ Antioq. 2010; 21 (2): 208-217.

12. Nabeel S, Danish G, Hegde U, Mull P. Parastyle: clinical significance and management of two cases. Int J Oral Maxillofac Pathol. 2012; 3 (3): 61-64.

13. Rodríguez C, Moreno F. Paramolar tubercle in the left maxillary second premolar: a case report. Dental Anthropol. 2006; 19: 65-69.

\author{
Dirección para correspondencia: \\ Freddy Moreno \\ E-mail: fmorenog@javerianacali.edu.com
}

